\title{
Bazı Aspir (Carthamus tinctorius L.) Hatlarının Ham Yağ Oranları ve Yăg Asidi Kompozisyonunun Belirlenmesi
}

\author{
Orhan KURT ${ }^{1}$ \\ Nurya ÇELIK ${ }^{1}$ \\ Merve GÖRE ${ }^{1}$ \\ A. Anıl SSENEL ${ }^{1}$ \\ M.Safa HACİKAMİLĞLU ${ }^{1}$ \\ Tuba ÖZYILMAZ ${ }^{1}$ \\ ${ }^{1}$ Ondokuz Mayıs Üniversitesi, Ziraat Fakültesi, Tarla Bitkileri Bölümü, Samsun \\ $\triangle$ : orhank@omu.edu.tr
}

Geliş (Received): 03.11.2017

Kabul (Accepted): 15.12.2017

\begin{abstract}
ÖZET: Bu araştırma Samsun ekolojik koşullarına Dünya aspir gen koleksiyonunda yer alan 36 aspir hattının tane verimi, ham yağ oranı, yağ verimi ve yağ asitleri kompozisyonunu saptamak amacıyla yapılmıştır. Deneme 20152016 kış yetiştirme sezonunda, Ondokuz Mayıs üniversitesi Ziraat Fakültesi deneme alanında yürütülmüştür. Araştırma sonucu; bitki başına tane veriminin 1.40-29.20 gr arasında, ham yağ oranının \%16.03-40.00 arasında, bitki başına yă̆ veriminin 0.22-7.25 gr arasında değiştiği, palmik asit oranının \%4.36-9.63 arasında, stearik asit oranının \%1.75-4.22 arasında, oleik asit oranının \%5.10-12.40 arasında, linoleik asit oranının \%73.58-88.46 arasında, linolenik asit oranının \%0.01-0.26 arasında ve araşıdonik asit oranının \%0.01-0.56 arasında değiştiği tespit edilmiştir. Sonuç olarak; 2, 6, 8, 11, 18, 21, 30, 33 ve 36 numaralı hatlardan oluşan 9 aspir hattı içeren gen havuzu ile adaptasyona yönelik olarak çalışmanın sürdürülmesinin uygun olacağına karar verilmiştir.
\end{abstract}

Anahtar Kelimeler: Aspir, yă̆ asidi kompozisyonu, yă̆ oranı,

\section{Determination of Oil content and Fatty Acid Composition of Some Safflower (Carthamus tinctorius L.) Cultivars}

\begin{abstract}
This research was carried out to determine the grain yield, crude oil ratio, oil yield and fatty acid composition of 36 safflower lines in Samsun ecological conditions world safflower gene collection. The experiment was carried out in the experimental field of the Agricultural Faculty of Ondokuz Mayis University during the winter growing season of 2015-2016. Research result; The rate of grain yield per plant is between 1.40-29.20 g, the ratio of crude oil is between 16.03-40.00\%, the oil yield per plant is between $0.22-7.25 \mathrm{~g}$, the palmitic acid content is between $4.36-9.63 \%$, the stearic acid ratio is between $1.75-4.22 \%$, the ratio of oleic acid is between $5.10-12.40 \%$, the ratio of linoleic acid is between $73.58-88.46 \%$, the ratio of linolenic acid is between $0.01-0.26 \%$ and the ratio of arachidic acid is $0.01-0.56 \%$. As a result; It has been decided to continue to work for adaptation with the gene pool containing 9 safflower lines consisting of lines 2, 6, 8, 11, 18, 21, 30, 33 and 36.

Keywords: Safflower, Fatty acid composition, oil content,
\end{abstract}

\section{GİRIŞ}

Türkiyede nüfus artışı ile birlikte, bitkisel yağ açığı her geçen yıl artış göstermektedir. Ancak, Türkiye'nin sahip olduğu ekolojik olanaklar, pek çok yağ bitkisi için geniş bir üretim potansiyeli arz etmektedir. Türkiye'nin bitkisel yağ üretiminde sahip olduğu potansiyel kaynaklardan birisi de aspir bitkisidir. Ancak uzun y1llardan beri ülkemizde yetiştirilmesine rağmen Türk tarımında aspir layık olduğu yeri henüz alamamıştır. Özellikle kurağa, tuzluluğa ve nispeten de soğuğa olan yüksek toleransı nedeniyle aspir, Türkiye'de de kurak tarım alanlarını değerlendirilebilecek bitkilerin başında gelmektedir.

Aspir tohumu \%25-40 oranında yăg ihtiva etmektedir. Dünyada, en fazla, linoleik asit bakımından zengin olan aspir çeşitlerinin tarımı yapılmaktadır. Ancak son yıllarda özellikle oleik asit tipi aspir çeşitleri de geliştirilmiştir (Armah-Agyeman ve ark., 2002).

Birçok olumlu özelliğine rağmen, dünya'da ve Türkiye'de aspir tarımının genişlemesinin önündeki en büyük engel tane veriminin düşük olmasıdır. Aspirden ekonomik düzeylerde verim alınabilmesi için, bir taraftan yetiştirme tekniği paketinin yeterli ve etkili olarak uygulanması, diğer taraftan da yüksek verimli, adaptasyon kabiliyeti geniş, hastalık ve zararlılara dayanıklı çeşitlerin geliştirilmesi gerekir. Bu noktadan hareketle Samsun Ekolojik Koşullarında Bazı aspir hatlarının ham yă̆ oranı, yağ verimi ve yağ asitleri kompozisyonunu belirlenmek amaciyla bu araştırma yürütülmüştür.

Yenice, Dinçer ve Remzibey'de yağ oranının sirasiyla \%24-25, \%25-28, \%35-40 olduğu (Engin, 1988), Ankara koşullarında yağ oranının kışlık ekimde \%28.20-33.30 arasında, yazlık ekimde \%29.80-38.60 arasında (Bayraktar, 1991), Antalya koşullarında ekim zamanı geciktikçe aspirde verimin önemli şekilde düştügünü (Baydar ve Turgut, 1992), bitki başına tohum veriminin 2.70-50.50 gr (Lakshmi Prayaga ve ark., 2003), 12.70-23.20 gr (Çelikoğlu, 2004) arasında değiştiği, oleik ve linoleik asit arasında çok yüksek ve negatif bir korelasyonun (-0.97) olduğunu (Knowles, 1989), tohum gelişimi boyunca meydana gelen sıcaklıkların yağ asitleri kompozisyonu üzerine önemli etkisinin olduğunu (Bartolomew, 1971), yağ içeriğinin $\% 13-46$, palmitik asidin \%3.90-6.80, stearik asidin $\% 1.10-4.50$, oleik asidin \%6.20-81.90 ve linoleik asidin \%11.00-83.10 arasinda (Johnson ve ark., 1999), en yüksek yağ oranının $\% 40$ olduğunu, linoleik asidin \%70.30-78.80, oleik asidin \%82.10-62.70 arasında değiştiği (Cazzato ve ark., 2001), Yenice ve Dinçer 
çeşitlerinin yüksek linoleik asit ile (sırasıyla \%79.10 ve \%75.40), yerli çeşitlerden Remzibey çeşidinin ise diğer iki çeşide göre nispeten daha yüksek oleik asit ile (\% 41.30) ile karakterize edildiği (Baydar, 2000), yağ verimi ile bitki başına tohum ağırlı̆̆ı, tohum verimi ve yağ oranı arasında 0.01 düzeyinde önemli ve olumsuz ilişkilerin olduğunu (Çelikoğlu, 2004), yağ içeriğinin \%14-36) olduğunu, tohum verimi ve yağ içeriği üzerine çevre şartlarının etkisinin fazla olduğu rapor edilmiştir (Çamaş ve Esendal, 2006).Yağ oranı \%21.8-27.8, palmitik asit \%6.0-8.5, stearik asit \%2.0-3.1, oleik asit $\%$ 7.8-30.6 ve linoleik asit \%60.0-81.6 olduğunu rapor etmiştir (Uysal, 2006),

\section{MATERYAL ve YÖNTEM}

\section{Araştırma Yeri Hakkında Genel Bilgiler}

Tarla denemesi, Ondokuz Mayıs Üniversitesi, Ziraat Fakültesi, deneme alanında yürütülmüştür. Deneme alanının toprakları killi (ağır) ve yüzlek bir yapıda olup, denizden yüksekliği 120 metredir. Deneme alanında, yetiştirme sezonu ve uzun yillar ortalaması olarak deneme periyodunda toplam $708 \mathrm{~mm}$ yağış düşmüş olup, uzun yılların yağış değerlerinden $(581 \mathrm{~mm})$ daha yüksektir. Ancak yetiştirme sezonu boyunca aylık ortalama sicaklık uzun yılların ortalamasına göre daha fazla aylık nispi nem ise daha düşük olarak gereçekleşmiştir.

\section{Materyal ve Metot}

$\mathrm{Bu}$ araştırmada; "Dünya Aspir Koleksiyonunda yer alan 23 ülkeye ait 36 aspir hattı ile standart olarak Balcı, Dinçer ve Remzibey aspir çeşidi kullanılmıştır. Dünya Aspir Koleksiyonuna ait materyal, ABD Ulusal Genetik Kaynakları Programından (https://www. ars-grin.gov) temin edilmiştir. Araştırmada genotipler Augmented deneme desenine göre 4 blok şeklinde ve bloklar arası 1 m olacak şekilde ekilmiştir. Ekimde her genotip 2 metre uzunluğunda, iki sıra biçiminde, sıra üzeri mesafesi 10 $\mathrm{cm}$ ve sıra aras mesafesi $40 \mathrm{~cm}$ olacak şekilde ekilmiştir.

Hasat, tam olgunluğa erişme aşamasında olmak üzere her bir hat için ayrı ayrı olacak biçimde yapılmıştır. Tane Verimi $\left(\mathrm{kgda}^{-1}\right)$; her parselden tesadüfi olarak seçilen 10 bitkiden harman sonrası elde edilen tohumlar tartılıp, ortalaması alınarak bitki başına tane verimi hesaplanmıştır. Harman sonrası her bir hatta ait tohumlardan ham yağ analizi Ankom XT15 extractor cihazı kullanılarak Anon (2017)'e, yağ asiti kompozisyonu GC-MS cihazı kullanılarak, Kurt ve ark. (2011)'a göre yapılamıştır. Yağ Verimi $\left(\right.$ gbitki $\left.^{-1}\right)$, yağ oranı ile bitki başına tane verimin çarpılması ile elde edilmiştir. Araştırmadan elde edilen verilerin değerlendirilmesinde SPSS programı kullanılmıştır.

\section{BULGULAR ve TARTIŞMA}

Tane Verimi: Bitki başına tane verimine ilişkin verilerin analizi sonucu incelenen hatlar arasinda istatistiki anlamda önemli bir farklılı̆̆ın olduğu belirlenmiştir. Bitki başına tane veriminin 1.4-29.2 gr arasında değiştiği, incelenen hatların ortalaması olarak 13.3 gr olduğu belirlenmiştir. İncelenen hatlardan 20 tanesinin bitki başına tane veriminin, ortalama tane veriminden daha fazla olduğu belierlenmiştir. İncelenen hatlar, standart çeşitler ile mukayese edildiğinde; incelenen hatlardan 28 tanesinin bitki başına tane veriminin en fazla tane verimin elde edildiği Dinçer çeşidinden $(6,5$ gr) fazla olduğu saptanmıştır (Çizelge 1).

Tane verimi, tarımsal açıdan en önemli karakter olup, genotip, çevre ve yetiştirme tekniği uygulamaları olmak üzere birçok faktörün tarafindan etkilenmektedir. Dolayısıyla bu faktörlerden her hangi birisi üzerinde meydana gelen olumlu ya da olumsuz durum verimi direk etkilemektedir. Tane verimi ile ilgili olarak daha önce yapılan çalışmalarda; bitki başına tane veriminin 12.2-19.2 gr (Öztürk, 1994), 52-80 gr (Uysal, 2006), 35.3-59.3 gr (Şaştı, 2007), 35.3-59.3 gr (Kıllı ve Ermiş, 2009), 54 gr (Şerefoğlu, 2009) ve 1.90-6.0 gr (Keleş, 2010) arasında değiştiği saptanmış olup, bu araştırmada elde edilen veriler (1,4-29,2 gr) ile uyumludur.

Ham Yağ Oranı: Araştırmadan ham yağ oranına ilişkin olarak elde edilen verilerin analizi sonucu incelenen hatlar arasinda istatistiki anlamda önemli bir farklılığın olduğu belirlenmiş olup, ham yağ oranının $\% 16.03-\% 40.0$ arasında değiştiği, incelenen hatların ortalaması olarak ham yağ oranının ise \%27.1 olduğu belirlenmiştir. İncelenen 36 hat arasında 15 hattın ham yağ oranının, hatların ortalama ham yağ oranından fazla olduğu belirlenmiştir. İncelenen hatlar, standart çeşitler ile mukayese edildiğinde; 36 hat içinde 6 hattın ortalama yă oranının, ham yağ oranının en fazla olduğu Balc1 çeşidinden (\%30.73) fazla olduğu belirlenmiştir (Çizelge 1).

Yağ oranı, tanedeki iç oranına bağlı olarak genetik faktörlerin etkisi ve ağırlıklı olarak çevre faktörlerinin konrolü altında ortaya çıkan bir karakterdir. Daha önce yapılan çalışmalarda yă̆ oranının; \%28-33 (Bayraktar, 1991), \%26.1-35.5 (Öztürk, 1994), \%25.2-30.5 (Kuz1l ve Şakar, 1997), \%25-40 (Engin, 1998), \%26-40 (Çelikoğlu, 2004), \%24.1-27.3 (Çamaş ve ark., 2005), \%14-36 (Çamaş ve Esendal, 2006), \%22-28 (Uysal, 2006), \%26.1-29.2 (Şaşti, 2007), \%40.1-48.3 (Yılmazlar ve Bayraktar, 2009), \%26.1.-29.2 (Kıll1 ve Ermiş, 2009), \%25.6-37.0 (Paşa (2009), \%27.5-29.7 (Keleş, 2010), \%31.2 (Süer, 2011), \%30.9-32.6 (İnan, 2014) ve \%25.4-35.0 (Sayllır, 2015) arasında değiştiği rapor edilmiştir. Bu çalışmalar değerlendirildiğinde; yağ oranının, \%14.0-48.3 arasında değişerek geniş bir varyasyona sahip olduğu söylenebilir. Bu varyasyonda; incelenen çeşitlerin genetik potansiyelleri ve adaptasyon yetenekleri en önemli etkiye sahiptir. Ayrica araştırmaların farklı ekolojik koşullarda ve farklı zamanlarda yapılması da ortaya çıkan varyasyonda belirleyici rol oynamıştır. $\mathrm{Bu}$ araştırmada elde edilen veriler $(\% 16,03-\% 40,0)$ daha önce elde edilen veriler ile uyumlu olup, aynı sınırlar içinde yer almaktadır.

Yağ Verimi: Araştırmadan bitki başına yağ verimine ilişkin olarak elde edilen verilerin analizi sonucu incelenen hatlar arasında istatistiki anlamda önemli bir farklılığın olduğu belirlenmiş̧tir. Araştırma sonucu bitki başına yağ veriminin $0.22-7.25$ gr arasında değiştiği, 
Çizelge 1. Genotiplerin tane verimi, yağ oranı, yağ verimi ve yağ asitleri kompozisyonlarına ilişkin veriler

\begin{tabular}{|c|c|c|c|c|c|c|c|c|c|c|}
\hline \multirow{2}{*}{$\begin{array}{l}\text { Hat } \\
\text { No }\end{array}$} & \multirow[b]{2}{*}{ IP } & \multirow{2}{*}{$\begin{array}{c}\text { Tane } \\
\text { verimi } \\
\text { (gr/bitki) }\end{array}$} & \multirow{2}{*}{$\begin{array}{c}\text { Yăg } \\
\text { oran1 } \\
(\%) \\
\end{array}$} & \multirow{2}{*}{$\begin{array}{c}\text { Yag } \\
\text { verimi } \\
\left(\text { grbitki }^{-1}\right)\end{array}$} & \multicolumn{6}{|c|}{ Yağ Asitlerinin Kompozisyonları (\%) } \\
\hline & & & & & Palmitik & Stearik & $\begin{array}{r}\text { Olei } \\
\mathrm{k}\end{array}$ & Linoleik & Linolenik & Araşidik \\
\hline 1 & 198843 & 12.30 & 26.21 & 3.22 & 5.56 & 3.22 & 9.6 & 81.43 & 0.01 & 0,14 \\
\hline 2 & 613465 & 1.40 & 16.03 & 0.22 & 4.36 & 1.96 & 5.1 & 88.46 & 0.02 & 0,16 \\
\hline 3 & 262442 & 7.00 & 24.61 & 1.72 & 6.16 & 2.45 & 10.2 & 80.79 & 0.01 & 0,43 \\
\hline 4 & 253522 & 15.80 & 22.59 & 3.57 & 5.68 & 2.47 & 10.1 & 81.41 & 0.01 & 0,32 \\
\hline 5 & 253570 & 16.60 & 29.62 & 4.91 & 5.64 & 3.20 & 11.2 & 79.49 & 0.01 & 0,42 \\
\hline 6 & 253520 & 19.40 & 27.28 & 5.29 & 5.59 & 2.08 & 7.12 & 84.89 & 0.04 & 0,20 \\
\hline 7 & 312275 & 15.40 & 24.68 & 3.80 & 5.57 & 2.65 & 11.0 & 80.47 & 0.02 & 0,22 \\
\hline 8 & 253531 & 29.20 & 24.85 & 7.25 & 6.31 & 2.42 & 7.7 & 83.15 & 0.03 & 0,38 \\
\hline 9 & 262447 & 14.80 & 20.33 & 3.00 & 6.64 & 2.68 & 9.3 & 81.22 & 0.04 & 0,15 \\
\hline 10 & 369850 & 8.40 & 26.26 & 2.21 & 6.59 & 2.84 & 9.3 & 81.11 & 0.02 & 0,12 \\
\hline 11 & 262444 & 4.20 & 28.56 & 1.20 & 6.33 & 2.49 & 9.2 & 81.71 & 0.01 & 0,29 \\
\hline 12 & 369853 & 26.40 & 23.54 & 6.21 & 5.78 & 2.41 & 8.8 & 82.74 & 0.03 & 0,20 \\
\hline 13 & 369847 & 18.70 & 24.85 & 4.65 & 5.29 & 2.70 & 9.3 & 82.45 & 0.01 & 0,19 \\
\hline 14 & 259997 & 17.00 & 21.01 & 3.57 & 7.17 & 3.92 & 9.7 & 78.66 & 0.26 & 0,26 \\
\hline 15 & 401581 & 9.80 & 28.99 & 2.84 & 5.44 & 2.27 & 8.9 & 83.31 & 0.01 & 0,04 \\
\hline 16 & 387820 & 20.60 & 24.86 & 5.12 & 5.06 & 4.22 & 7.8 & 82.70 & 0.02 & 0,15 \\
\hline 17 & 380800 & 10.70 & 29.65 & 4.26 & 6.34 & 1.95 & 7.7 & 83.92 & 0.03 & 0,05 \\
\hline 18 & 405999 & 18.00 & 31.43 & 5.65 & 5.34 & 1.75 & 8.2 & 84.63 & 0.01 & 0,12 \\
\hline 19 & 250833 & 14.40 & 30.38 & 5.04 & 5.13 & 1.99 & 8.4 & 84.25 & 0.01 & 0,15 \\
\hline 20 & 304437 & 16.60 & 30.62 & 3.27 & 5.98 & 1.89 & 7.9 & 84.33 & 0.01 & 0,01 \\
\hline 21 & 386174 & 26.00 & 26.48 & 6.88 & 6.41 & 2.18 & 9.1 & 82.22 & 0.01 & 0,13 \\
\hline 22 & 253895 & 22.00 & 23.12 & 5.08 & 9.63 & 3.99 & 12.4 & 73.58 & 0.01 & 0,35 \\
\hline 23 & 301055 & 9.20 & 27.38 & 2.51 & 5.97 & 2.34 & 9.6 & 81.79 & 0.04 & 0,29 \\
\hline 24 & 532619 & 16.90 & 31.40 & 5.30 & 6.21 & 1.92 & 9.9 & 81.78 & 0.02 & 0,14 \\
\hline 25 & 306613 & 5.20 & 27.07 & 1.40 & 6.49 & 1.80 & 7.8 & 83.75 & 0.01 & 0,12 \\
\hline 26 & 306602 & 2.50 & 26.01 & 0.65 & 8.80 & 3.72 & 9.0 & 78.20 & 0.02 & 0,29 \\
\hline 27 & 250611 & 3.40 & 27.66 & 0.94 & 6.27 & 2.31 & 8.5 & 82.74 & 0.01 & 0,22 \\
\hline 28 & 237550 & 10.20 & 32.57 & 3.32 & 6.05 & 2.24 & 8.1 & 83.34 & 0.01 & 0,24 \\
\hline 29 & 226993 & 9.80 & 25.99 & 2.54 & 6.03 & 2.33 & 10.3 & 81.02 & 0.01 & 0,36 \\
\hline 30 & 198990 & 5.10 & 33.40 & 1.70 & 5.29 & 2.5 & 11.2 & 80.8 & 0.01 & 0,19 \\
\hline 31 & 251262 & 14.2 & 22.05 & 3.13 & 6.02 & 2.60 & 11.2 & 79.99 & 0.01 & 0,14 \\
\hline 32 & 195895 & 3.30 & 26.37 & 0.87 & 5.77 & 2.82 & 6.9 & 84.36 & 0.01 & 0,13 \\
\hline 33 & 393498 & 18.80 & 34.18 & 6.42 & 5.98 & 2.86 & 8.5 & 82.09 & 0.01 & 0,56 \\
\hline 34 & 393499 & 20.20 & 30.11 & 6.08 & 5.83 & 2.4 & 9.4 & 82.22 & 0.02 & 0,14 \\
\hline 35 & 537608 & 13.90 & 25.54 & 3.55 & 7.24 & 2.17 & 8.3 & 82.18 & 0.02 & 0,10 \\
\hline 36 & 560175 & 1.50 & 40.00 & 0.60 & 6.18 & 2.21 & 9.9 & 81.60 & 0.01 & 0,10 \\
\hline \multicolumn{2}{|c|}{ Remzibey } & 1.10 & 23.41 & 0.25 & 6.1 & 2.55 & 24.7 & 66.16 & 0.01 & 0.49 \\
\hline \multicolumn{2}{|c|}{ Balcı } & 3.20 & 30.73 & 1.04 & 6.26 & 2.09 & 8.4 & 82.89 & 0.02 & 0.30 \\
\hline \multicolumn{2}{|c|}{ Dinçer } & 6.50 & 28.09 & 1.62 & 8.75 & 3.34 & 8.6 & 78.76 & 0.01 & 0.51 \\
\hline \multicolumn{2}{|c|}{ Ortalama } & 13.30 & 27.10 & 3.63 & 6.12 & 2.56 & 9.07 & 82.02 & 0.02 & 0.21 \\
\hline \multicolumn{2}{|c|}{$\begin{array}{l}\text { Standart } \\
\text { Sapma }\end{array}$} & 7.3 & 4.44 & 1.91 & 0.96 & 0.62 & 1.42 & 2.4 & 0.04 & 0.12 \\
\hline
\end{tabular}

incelenen hatların ortalaması olarak bitki başına yağ veriminin 3.55 gr olduğu belirlenmiştir. Araştırmada incelenen hatlardan 5, 6, 7, 8, 12, 13, 16, 17, 18, 19, 21, $22,24,33$, ve 34 numaralı hat olmak üzere toplam 15 hattın incelenen 36 hattın ortalama bitki başına yağ verimine göre daha fazla bitki başına yağ verimine sahip oldukları belirlenmiştir. Araştırmada incelenen hatlar standart çeşitler ile mukayese edildiğinde; bitki başına tane veriminin en fazla olduğu Standart Dinçer aspir çeşide (1.62 gr) göre incelenen 36 hat içininde 1, 3, 4, 5,
$6,7,8,9,10,12,13,14,15,16,17,18,19,20,21,22$, $23,24,28,29,30,31,33,34$, ve 35 numaralı hatlar olmak üzere toplam 29 hattın daha fazla bitki başına yağ verimine sahip oldukları tespit edilmştir (Çizelge 1).

Bitki başına yağ verimi; bitki başına tane verimi ve yağ oranının bağlı olarak ortaya çıkan bir karakterdir. Yağ verimine ilişkin olarak daha önce yapılan çalışmalarda aspirde dekara yă̆ veriminin; $36.8-41.5 \mathrm{~kg}$ (Tunçtürk, 1998), 58.6-115.0 kg (Çelikoğlu, 2004), 23.78-28.83 kg (Geçgel, 2004), 41.6-70.1 kg 
(Koutroubas ve Papakosta, 2005), 62.5-103.1 kg (Şaşti, 2007), 62.5-103.1 kg (Kıllı ve Ermiş, 2009), 18.2-33.3 $\mathrm{kg}$ (Keleş, 2010), 49.2-79.2 kg (Süer, 2011), 58.12$85.51 \mathrm{~kg}$ (Kunt, 2012) ve 49.2-87.3 kg (Sayllır, 2015) arasında değiştiği ortaya konmuştur. Bu çalışmada elde edilen yă verimi değerleri, aspir bitkisinde daha önce elde edilen yağ verimi değerleriyle büyük oranda uyum arz etmektedir.

Yağ Asilerinin Kompozisyonlart: Araştırma sonucu yağ asidi kompozisyonunda yer alan palmitik, stearik, oleik, linoleik, linolenik ve araşıdik yağ asitlerinin dağ 1 lımı incelendiğinde; palmik asit oranının \%4.369.63 arasında, stearik asit oranının \% 1.75-4.22 arasında, oleik asit oranının \%5.1-12.4 arasında, linoleik asit oranının \% 73.58-88.46 arasında, linolenik asit oranının $\% 0.01-0.26$ arasında ve araşıdonik asit oranının \%0.010.56 arasında yer aldığı tespit edilmiştir. Araştırmada incelenen 36 aspir hattı içerisinde en yüksek palmitik asit oranı 22 numaralı hattan, en yüksek stearik asit oranı 16 numaralı hattan, en yüksek oleik asit oran 15 , 30 ve 31 numaralı hatlardan, en yüksek linoleik asit oranı 2 numaralı hattan, en yüksek araşıdonik asit oranı 33 numaralı hattan elde edilmiștir. İncelenen yağ asitleri içerisinde linoleik asit oranı bariz bir biçimde diğer yağ asitlerinden farklılık göstermektedir (Çizelge 1). Aspir grupları, yăg asidi kompozisyonuna göre oleik ya da linoleik grubu olarak ayrılmaktadır. Bu araştırmada incelenen bütün hatların linoleik asit oranı \%70'den daha fazladır. Dolayısıyla incelenen bütün hatlar linoleik tipi aspir grubuna girdiği belirlenmiştir.

\section{SONUÇ}

Araştırmanın sonuçlarına göre; bitki başına tane verimi, ham yağ oranı, bitki başına yağ verimi ve yağ asidi kompozisyonu bakımından değerlendirildiğinde; $2,6,8$, $11,18,21,30,33$ ve 36 numaralı hatlardan oluşan 9 hattı içeren gen havuzu ile adaptasyon ve seleksiyona yönelik olarak çalışmaların devam ettirilmesinin uygun olacaktır.

\section{KAYNAKLAR}

Anon 2017. ANKOM Technology Method Analytical Procedure XT10/XT10i/XT15/XT15i (www.ankom.com, erișim 13.07.2017)

Armah-Agyeman G, Loiland J, Karow R, Hang AN 2002. Safflower. Oregon State University.

Bartholomew SB 1971. Temperature Effects on the Fatty Acid Composition of Developing in Safflower (Carthamus tinctorius L.). MS Thesis Univercity of California.

Baydar H, Turgut İ 1992. Aspir (Carthamus tinctorius L.)'in Antalya Koşullarında Kışlık Olarak Yetiștirme Olanakları. Akdeniz Ün. Ziraat Fak. Derg., (1-2): 75-92.

Baydar H 2000. Gibberellik Asidin Aspir (Carthamus tinctorius L.)'de Erkek Kısırlık, Tohum Verimi ile Yağ ve Yağ Asitleri Sentezi Üzerine Etkisi. Tr. J. Biology, (24): 159-168.

Bayraktar N 1991. Kışlık ve Yazlık Aspir (Carthamus tinctorius $L$ ) Döllerinde Verimi Etkileyen Faktörler. Ankara Ü. Ziraat Fak. Yay. 1215. Bilimsel
Araştırma ve İncelemeler, s665.

Cazzato E, Borazio L, Corleto A 2001. Grain Yield, Oil Content and Earliness of Flowering of Hybrids and Open- Pollinated Safflower in Southern Italy.Vth International Safflower Conference, 23-27 July, Wiliston, U.S.A.

Çamaş N, Ayan AK, Çrak C 2005. Relationships Between Seed Yield and Some Characters of Safflower (Carthamus tinctorius L.) Cultivars Grown in the Middle Black Sea Conditions. VI. International Safflower Conference, 6-10 June, İstanbul.

Çamaş N, Esendal E 2006. Estimates of Broad-sense Heritability for Seed Yield and Yield Components of Safflower (Carthamus tinctorius L.), Hereditas Lund, Sweden.

Çelikoğlu F 2004. Eskişehir Koşullarında Geliştirilen Aspir (Carthamus tinctorius L.) Hatlarında Verim Kriterlerinin Belirlenmesi. Ankara Ü. Fen Bil. Enst. Tarla Bitkileri ABD Y. Lisans Tezi.

Engin D 1988. Aspir Tarımı ve Aspir'in Endüstride Kullanım Alanları. T.C. Tarım Orman ve Köy İşleri Bakanlığı Geçit Kuşağı Tarımsal Araştırma Enstitüsü Müdürlüğü, Eskișehir.

Geçgel Ü 2004. Değişik Ekim ve Hasat Dönemlerinin Aspir (Carthamus tinctorius L.) Yağının Bazı Fiziksel, Kimyasal ve Oksidatif Özellikleri Üzerine Etkileri. Trakya Ü. Fen Bil. Ens., Gıda Mühendisliği ABD, Doktora Tezi.

Johnson RC, Bergman JW, Flynn CR 1999. Oil and Meal Characteristics of Core and Non-core Safflower Accessions from the USDA Collection. Genet. Res. Crop Evol., (46): 611-618.

İnan D, Algan N 2014. İzmir Bornova Koşullarında Yazlık ve Kışlık Bazı Aspir Çeşitlerinin Verim ve Verim Unsurlarının Karşılaştırılması. Ege Ü. Fen Bil. Ens. Tarla Bitkileri ABD, Doktora Tezi.

Keleş R, Öztürk Ö 2010. Farklı Ekim Zamanlarının Bazı Aspir Çeşitlerinde Verim ve Kalite Üzerine Etkileri. Tarım Bilimleri Araştırma Derg., 5 (1):112117.

Kıllı F, Ermiş H 2009. Kahramanmaraş Koşullarında Farklı Miktarlarda ve Zamanlarda Uygulanan Azotun Aspir (Carthamus tinctorius L.)'de Tohum Verimi, Verim Unsurları ve Tohumun Makro-Mikro Element İçeriğine Etkisi. Sütçü İmam Ü. Fen Bil. Ens. Tarla Bitkileri ABD Yüksek Lisans Tezi.

Kızıl S, Şakar D 1997. Diyarbakır Ekolojik Koşullarında Aspirde (Carthamus tinctorius L.) Uygun Ekim Zamanının Saptanması Üzerine Bir Çalışma. Türkiye II. Tarla Bitkileri Kongresi, 22-25 Eylül, Samsun.

Knowles PF 1989. Safflower. (Oil Crops of the World: ed. Robbelen G, Downey RK, Ashri A), McGrawHill Publishers, London) 361-374.

Koutroubas S, Papakosta DK 2005. Adaptation, Grain Yield and Oil Content of Safflower in Greece. VIth International Safflower Conference, 06-10 June, İstanbul.

Kunt N, Akınerdem F 2012. Aspir (Carthamus 
tinctorius L.)'de Frklı Sira Üzeri Mesafelerinin ve Yabanc1 Ot Mücadelesinin Verim ve Kalite Üzerine Etkisi. Selçuk Ü. Fen Bil. Ens. Tarla Bitkileri ABD Yüksek Lisans Tezi.

Kurt O, Uysal H, Demir A, Özgür Ü, Kılıç R 2011. Samsun Ekolojik Koşullarına Adapte Olabilecek Kışlık Aspir (Carthamus tinctorius L.) Genotioplerinin Belirlenmesi Üzerinde Bir Araştırma. Anadolu Tarım Bilim. Derg., 26(3):212216.

Lakshmi Prayaga, P, Lakshmamma P, Padmavthi P 2003. Characterization of Safflower Germplasm for Physiological Traits. Sesame and Safflower Newsletter, (18): 90-92, Cordoba, Spain.

Öztürk Ö 1994. Konya Ekolojik Şartlarında Bazı Aspir (Carthamus tinctorius L.) Çeşitlerinde Verim ve Verim Unsurlarının Tespiti. Selçuk Ü. Fen Bil. Ens. Tarla Bitkileri ABD Yüksek Lisans Tezi.

Paşa C, Esendal E, Arslan B 2009. Kışlık ve Yazlık Ekimin Aspir (Carthamus tinctorius L.) Bitkisinin Verimi ve Bitkisel Özelliklerine Etkisi. Türkiye VIII. Tarla Bitkileri Kongresi, 19-22 Ekim, Hatay.

Uysal N 2006. Isparta Populasyonundan Geliştirilen Aspir (Carthamus tinctorius L.) Hatlarının (Gelendost-1 ve Gelendost-2 ) Tarımsal ve Teknolojik Özelliklerinin Belirlenmesi. Süleyman Demirel Ü. Fen Bil. Ens. Tarla Bitklieri ABD Y. Lisans Tezi.

Sayılır C 2015. Bazi Aspir (Carthamus tinctorius L.) Çeşitlerinin İzmir Menemen Ekolojik Koşullarında Verim ve Verim Unsurlarının Belirlenmesi. Adnan
Menderes Ü. Fen Bil. Ens. Tarla Bitkileri ABD Yüksek Lisans Tezi.

Süer İE 2011. Bazı Aspir (Carthamus Tinctorius L.) Çeşitlerinde Farklı Gelişme Dönemlerinde Yapılan Sulamaların Verim Ve Bazı Agronomik Özellikler Üzerine Etkisi. Çukurova Ü. Fen Bil. Ens. Tarla Bitkileri ABD Yüksek Lisans Tezi.

Şaşti H 2007. Kahramanmaras Kosullarında Farklı Miktarlarda ve Zamanlarda Uygulanan Azotun Aspir (Carthamus tinctorius L.)'de Tohum Verimi, VerimUnsurları, Yağ Oranı Ve Tohumun MakroMikro Element İçeriğine Etkisi. Kahramanmaras Sütçü İmam Ü. Fen Bil. Ens. Tarla Bitkileri ABD Yüksek Lisans Tezi.

Şerefoğlu AH. 2009. Kahramanmaraş Koşullarında Farklı Sira Üeri Mesafelerinde Ekilen Aspir (Carthamus Tinctorius L.) Bitkisinin Verimliliği ve Yağ Asidi Kompozisyonu Üzerine Potasyum Uygulamasının Etkisi. Sütçü İmam Ü. Fen Bil. Ens. Tarla Bitkileri ABD Yüksek Lisans Tezi.

Tunçtürk M 1998.Van Ekolojik Koşullarında Azotlu Gübre Form ve Dozlarının Aspir (Carthamus tinctorius L.)'de Verim ve Verim Unsurları Üzerine Etkileri. Yüzüncü Yıl Ü. Fen Bil. Ens. Tarla Bitkileri ABD Yüksek Lisans Tezi.

Y1lmazlar B, Bayraktar N 2009. Konya Şartlarında Farklı Ekim Zamanlarının Bazı Aspir (Carthamus tinctorius L.) Çeşitlerinde Önemli Tarımsal Karakterler Üzerine ve Verime Etkisi. Türkiye VIII. Tarla Bitkileri Kongresi, 19-22 Ekim, Hatay. 